\title{
DESENVOLVIMENTO E PRODUÇÃO DE BANANEIRAS THAP MAEO E PRATA-ANÃ COM DIFERENTES NÍVEIS DE ADUBAÇÃO NITROGENADA E POTÁSSICA ${ }^{1}$
}

\author{
RAFAEL FELIPPE RATKE ${ }^{2}$, SILVIA CORRÊA SANTOS ${ }^{3}$, \\ HAMILTON SERON PEREIRA ${ }^{4}$, EDICARLOS DAMACENA DE SOUZA 5 , \\ MARCO AURÉLIO CARBONE CARNEIRO 6
}

RESUMO - O objetivo desta pesquisa foi caracterizar o desenvolvimento e o rendimento de cultivares de bananeira no sudoeste de Goiás e adequar os níveis de adubação combinada de $\mathrm{N}$ e $\mathrm{K}$. O experimento foi conduzido em Latossolo Vermelho distrófico, no município de Rio Verde, Goiás. Os tratamentos consistiram em cinco doses crescentes e combinadas de $\mathrm{N}$ e K (N0/K0 - $0 \mathrm{~kg} \mathrm{ha}^{-1} \mathrm{ano}^{-1}$ de $\mathrm{N}$ e $0 \mathrm{~kg} \mathrm{ha}^{-1} \mathrm{ano}^{-1} \mathrm{de} \mathrm{K}$; N1/ $\mathrm{K} 1$ - $150 \mathrm{~kg} \mathrm{ha}^{-1} \mathrm{ano}^{-1}$ de Ne $200 \mathrm{~kg} \mathrm{ha}^{-1} \mathrm{ano}^{-1}$ de $\mathrm{K}$; N2/K2 - $300 \mathrm{~kg} \mathrm{ha}^{-1} \mathrm{ano}^{-1}$ de N e $450 \mathrm{~kg} \mathrm{ha}^{-1} \mathrm{ano}^{-1} \mathrm{de}^{-1}$ $\mathrm{K}$; N3/K3 - $450 \mathrm{~kg} \mathrm{ha}^{-1} \mathrm{ano}^{-1}$ de N e $600 \mathrm{~kg} \mathrm{ha}^{-1} \mathrm{ano}^{-1}$ de K; N4/K4 - $600 \mathrm{~kg} \mathrm{ha}^{-1}$ ano $^{-1}$ de N e $800 \mathrm{~kg} \mathrm{ha}^{-1}$ ano $^{-1}$ de K), aplicadas em duas cultivares de banana, Thap Maeo e a Prata-Anã. As avaliações realizadas nas bananeiras foram: altura das plantas, diâmetro do pseudocaule e número de folhas aos 150 dias após plantio (DAT) e na época do florescimento. As plantas foram avaliadas no florescimento e na colheita das bananeiras, observando os seguintes componentes de produção: intervalo em dias entre o plantio e o florescimento, número de folhas na colheita, número de pencas por cacho e frutos na segunda penca, comprimento do engaço e dos frutos na segunda penca, diâmetro do engaço e dos frutos na segunda penca e peso do cacho, engaço e dos frutos na segunda penca. Amostras foliares das bananeira foram realizadas no seu florescimento e foram analisadas para obter os teores de macro e micronutrientes. Com os dados dos componentes de produção, calcularam-se o índice de durabilidade das folhas e a taxa de crescimento absoluto do pseudocaule das bananeiras. Os resultados foram submetidos a ANOVA e regressão, e a comparação de médias foi feita pelo teste de Tukey. Os atributos de desenvolvimento, a produção e os teores de macronutrientes e micronutrientes nas folhas da Thap Maeo e Prata-Anã foram influenciados pelas diferentes doses combinadas de $\mathrm{N} \mathrm{e} \mathrm{K}$. O menor intervalo de dias entre o florescimento foi encontrado com as doses de $300 \mathrm{~kg} \mathrm{ha}^{-1}$ de N e $450 \mathrm{~kg} \mathrm{ha}^{-1}$ de K na Thap Maeo. Não houve melhor combinação das doses de N e K para os parâmetros de desenvolvimento, produção e teores foliares na Prata-Anã.

Termos para indexação: Musa spp., Latossolo Vermelho distrófico, nutrição de plantas, teores foliares.

\section{GROWTH AND YIELD OF BANANA TREES CULTIVAR THAP MAEO AND PRATA-ANÃ WITH DIFFERENT LEVELS OF NITROGEN AND POTASSIUM FERTILIZATION}

\begin{abstract}
The objective of this research is to characterize the development and yield of banana trees in the Southwest region of Goiás and to adjust different combination levels of $\mathrm{N}$ and $\mathrm{K}$. The experiment was conducted in dystrophic red Oxisol, in the district of Rio Verde, Goiás, and consisted on five doses of increasing rates of $\mathrm{N}$ and $\mathrm{K}\left(\mathrm{N} 0 / \mathrm{K} 0-0 \mathrm{~kg} \mathrm{ha}^{-1}\right.$ year $^{-1}$ of $\mathrm{N}$ and $0 \mathrm{~kg} \mathrm{ha}^{-1}$ year ${ }^{-1}$ of $\mathrm{K}$; $\mathrm{N} 1 / \mathrm{K} 1-150 \mathrm{~kg} \mathrm{ha}^{-1}$ year ${ }^{-1}$ of N and $200 \mathrm{~kg} \mathrm{ha}^{-1}$ year ${ }^{-1}$ of $\mathrm{K}$; N2/K2 - 300 kg ha ${ }^{-1}$ year $^{-1}$ of $\mathrm{N}$ and $450 \mathrm{~kg} \mathrm{ha}^{-1}$ year ${ }^{-1}$ of $\mathrm{K}$; N3/ $\mathrm{K} 3-450 \mathrm{~kg} \mathrm{ha}^{-1}$ year $^{-1}$ of $\mathrm{N}$ and $600 \mathrm{~kg} \mathrm{ha}^{-1}$ year $^{-1}$ of K; N4/K4 - $600 \mathrm{~kg} \mathrm{ha}^{-1}$ year $^{-1}$ of N and $800 \mathrm{~kg} \mathrm{ha}^{-1}$ year ${ }^{-1}$ of K), applied to two cultivars of bananas, Thap Maeo and Prata-anã. The evaluations conducted in the plants were: plant height, pseudo stem diameter and leaf number at 150 days after planting (DAT) and at flowering. The plants were assessed at the flowering and at the harvest observing the following yield components: the time elapsed between planting and flowering, leaf number at harvest, number of bunch per cluster and number of fruits in the second bunch, the length of the stem and the fruits in the second bunch, the diameter of the stem and fruits in the second bunch and the weight of the bunch, the stem and the fruits in the second bunch. The banana plants were sampled at flowering for analyzing the nutrient content. With the data of yield components were calculated durability index of the leaf and absolute rate of banana growth. The results were submitted to ANOVA and regression, and the mean comparison by the Tukey test. The attributes of development, production and leaf levels of nutrients in Thap Maeo and Prata-Anã were influenced by different rates of combined $\mathrm{N}$ and $\mathrm{K}$. The smallest interval between flowering days was found with rates of $300 \mathrm{~kg} \mathrm{ha}^{-1}$ of $\mathrm{N}$ and $450 \mathrm{~kg} \mathrm{ha}^{-1}$ of $\mathrm{K}$ in Thap Maeo. There was no better combination of $\mathrm{N}$ and $\mathrm{K}$ parameters for the development, production and leaf levels of nutrients in Prata-Anã.

Index terms: Musa spp.,red dystrophic Oxisol, plant nutrition, leaf levels.
\end{abstract}

\footnotetext{
1(Trabalho 098-11). Recebido em: 23-03-2011. Aceito para publicação em: 06-09-2011. Parte da Dissertação de Mestrado do Primeiro Autor. ${ }^{2} \mathrm{Eng}^{\circ} \mathrm{Agr}^{\circ}$, Doutor em Agronomia, R. Dona Stela no 151, Setor Negrão de Lima, Goiânia-GO, CEP:74650-100. E-mail: rfratke@gmail.com ${ }^{3}$ Eng $^{0}$ Agr ${ }^{\mathrm{a}}$, Prof. Associado, UFGD, FCA, C. P.: 322, Dourados-MS, CEP: 79825-070. E-mail: scscorrea@yahoo.com.br ${ }^{4} \mathrm{Eng}^{\circ} \mathrm{Agr}^{\circ}$, Prof. Adjunto, UFU, ICA, C. P.: 593, Uberlândia-MG, CEP: 38400-902. E-mail: hseron@uol.com.br ${ }^{5}$ Prof. Associado, UFG, Câmpus de Jataí, Rod. BR 364, Km192, Jataí-GO, CEP: 75800-000, E-mail: carbonecaneiro@yahoo.com.br ${ }^{6}$ Eng $^{0}$. Agro ., Pós-Doutorando, PPGA/UFG, Jataí, Rod. BR 364, Km192, Jataí-GO, CEP: 75800-000. E-mail: edidamacena2000@yahoo.com.br
} 


\section{INTRODUÇÃO}

A área com a cultura da banana colhida no Brasil, na safra de 2010, foi de aproximadamente 507.230 ha, a produção de 6,9 milhões de toneladas e a produtividade média em torno de 14,5 t ha ${ }^{1}$ (IBGE, 2010). Entretanto, o Brasil pode aumentar a produtividade por área com manejos adequados de produção, como, por exemplo, a Índia, que apresenta uma produtividade de 24,74 $\mathrm{t} \mathrm{ha}^{-1}$ (EPAGRI, 2009).

O Centro-Oeste correspondeu com 3,69\% da produção nacional de banana no ano de 2010 . Sendo que o Estado de Goiás foi responsável por 73,48\% dessa produção, obtida em uma área plantada de 14.986 ha (IBGE, 2010) e com produtividade média de $13 \mathrm{t} \mathrm{ha}^{-1}$. Mesmo sendo pouco expressiva a produção de banana em Goiás, essa produção atende à demanda local dessa fruta.

A bananicultura no mundo conta com um número expressivo de cultivares, mas quando se considera preferência dos consumidores, produtividade, tolerância a pragas, porte adequado, resistência à seca e ao frio, restam poucas cultivares com potencial agronômico para utilização comercial. As cultivares mais difundidas no país e plantadas são as bananas tipo prata (Prata, Pacovan e Prata-Anã), responsável por $60 \%$ da área cultivada, a Maçã, a Mysore, as bananas tipo Cavendish (Nanica, Nanicão e Grande Naine), preferidas pelo mercado internacional, e as bananas tipo Terra, sendo que existem outras cultivares em menor proporção, como as do tipo Figo ou Bluggoe, as do tipo Caru e do tipo Ouro. Uma das estratégias para a solução dos problemas mencionados é o desenvolvimento de cultivares resistentes a pragas e doenças, que sejam precoces, produtivas e aceitas pelo mercado, por meio de programas de melhoramento genético, bem como sua avaliação e caracterização em áreas de produção (DONATO et al., 2006).

As bananeiras são muitos exigentes em adubação quando comparadas a outras frutíferas, principalmente em $\mathrm{N}$ e $\mathrm{K}$ devido ao seu desenvolvimento rápido e sua grande área foliar e produção. Neste sentido, vários estudos de adubação de bananeiras e adubação de $\mathrm{N}$ e $\mathrm{K}$ demonstram que as produções de bananas dependem diretamente destes elementos em equilíbrio na nutrição destas plantas (BORGES et al., 1997; BRASIL et al., 2000; CANTARUTTI et al., 2000; ALVAREZ et al., 2001).

Guerrero e Gargban (2002) verificaram que a adubação de $\mathrm{K}$ e $\mathrm{N}$ em bananeira pode ser feita pela proporção de $2: 1$ ou 3:1, ou seja, a dose de K é duas ou três vezes a dose recomendada de $\mathrm{N}$, onde os resultados foram melhores na proporção de 2:1. A relação entre a adubação nitrogênada e a adubação potássica na cultura da bananeira foi avaliada em vários trabalhos com a dosagem de $\mathrm{K}$ sempre superior à de N. Essas proporções foram utilizadas para testar níveis crescentes de $\mathrm{N}$ e $\mathrm{K}$ em cultivares de banana, para posteriormente recomendar uma adubação adequada. Assim, pesquisas com adubação nitrogenada e potássica mostram que as doses utilizadas de $\mathrm{N}$ são de 30 a $50 \%$ menores que as doses utilizadas de K. (BORGES et al., 1997; BRASIL et al., 2000; TEIXEIRA, 2000; SILVA et al., 2003; GUERRA et al., 2004; SOUSA et al., 2004; WEBER et al., 2006).

Dessa forma, este trabalho teve como objetivo avaliar a influência das doses combinadas de nitrogênio e potássio no desenvolvimento e no rendimento de produção em duas cultivares de bananeira Thap Maeo e Prata-Anã, em Latossolo Vermelho distrófico, no município de Rio Verde, Goiás.

\section{MATERIAL E MÉTODOS}

O experimento foi instalado em outubro de 2006, no Centro Tecnológico Comigo (CTC), Anel Viário Km 12, município de Rio Verde-GO, situado nas coordenadas $17^{\circ} 45^{\prime} 44,72^{\prime \prime} \mathrm{S}$ e $51^{\circ} 02^{\prime} 12,74^{\prime \prime}$ WOsolo da área de pesquisa foi classificado como Latossololo Vermelho distrófico. O solo foi amostrado no dia 12-05-2006, nas camadas de 0 a10 cm, 10 a $20 \mathrm{~cm}, 20$ a $40 \mathrm{~cm}$ e 40 a $60 \mathrm{~cm}$ de profundidade e, posteriormente, analisado, apresentando os resultados de atributos químicos e físicos na Tabela 1.

O clima da região, segundo Köeppen, é classificado como Aw. O solo da área de plantio das bananeiras foi cultivado com soja na safra de 2005/2006. O solo ficou em pousio de 22-022006 até o transplantio das mudas das cultivares de bananeiras testadas, realizado no dia 26-10-2006.

O critério para a correção do solo foi baseado no método da saturação por bases, elevando a saturação por bases do solo da área do plantio das bananeiras para $70 \%$, segundo recomendado para a cultura da banana por Lopes (1990), utilizando os dados da análise de solo amostrado, conforme Tabela 1. Assim, foi necessária a aplicação de 2,42 t ha $^{-1}$ de calcário dolomítico com PRNT de $85 \%$, que foram aplicadas a lanço, superficialmente, na área do experimento.

O delineamento de blocos casualizados com parcelas subdivididas foi utilizado para montar esta 
pesquisa. As parcelas foram constituídas por duas cultivares de bananeira e as subparcelas constituídas por cinco doses combinadas de $\mathrm{N}$ e $\mathrm{K}$, com três repetições. As parcelas foram constituídas pelas cultivares de banana Thap Maeo (cultivar resistente à Sigatoka-Negra e ao Mal-do-Panamá) e a PrataAnã (cultivar comercial do Subgrupo Prata). As subparcelas consistiram em cinco doses crescentes e combinadas de nitrogênio $(\mathrm{N})$ e potássio $(\mathrm{K})$ descritas na Tabela 2, utilizando como fonte $\mathrm{o}$ sulfato de amônio $(20 \% \mathrm{~N})$ e o cloreto de potássio $\left(58 \% \mathrm{~K}_{2} \mathrm{O}\right)$.

O bananal foi implantado com mudas do tipo chifre em cova de plantio, com as seguintes dimensões $60 \times 60 \times 60 \mathrm{~cm}$. Nas bordaduras das parcelas, foram transplantadas outras cultivares, como Caipira, Nanica, Nanicão e Pratinha devido à baixa disponibilidade de mudas de Thap Maeo e Prata-Anã. O bananal não foi irrigado visando à adaptação às condições climáticas do município de Rio Verde-GO. O experimento ocupou uma área de $108 \mathrm{~m} \mathrm{x} 40 \mathrm{~m}\left(4.320 \mathrm{~m}^{2}\right)$, sendo as plantas dispostas no espaçamento de $3 \mathrm{~m}$ x $2 \mathrm{~m}$ e cada subparcela constituída de quatro plantas centrais na parcela.

O parcelamento da adubação foi realizado da seguinte maneira: $10 \%$ na primeira aplicação, $25 \%$ na segunda aplicação, $35 \%$ na terceira aplicação e $30 \%$ na quarta aplicação. As aplicações desses adubos ocorrem aos 60; 90; 120 e 150 dias após o transplantio das mudas (DAT). A aplicação foi feita na superfície do solo em semicírculo numa faixa de 30 a $40 \mathrm{~cm}$ do pseudocaule. A adubação fosfatada foi realizada em única dose no plantio das mudas de bananeira, na dosagem de $90 \mathrm{~g} \mathrm{cova}^{-1}$ de $\mathrm{P}_{2} \mathrm{O}_{5}$, ou seja, $150 \mathrm{~kg} \mathrm{ha}^{-1}$ de $\mathrm{P}_{2} \mathrm{O}_{5}$ usando como fonte o fertilizante superfosfato-simples $\left(18 \%\right.$ de $\left.\mathrm{P}_{2} \mathrm{O}_{5}\right)$ como recomendado por Cordeiro (2000).

As avaliações realizadas foram: altura das plantas, diâmetro do pseudocaule e número de folhas aos 150 dias após transplantio (DAT), na época do florescimento e na colheita das bananeiras. A altura das plantas foi medida utilizando uma trena métrica de $5 \mathrm{~m}$, semiflexível, onde se media do solo até o topo da roseta foliar. O diâmetro do pseudocaule foi verificado utilizando um paquímetro de madeira adaptatado para medidas maiores de $15 \mathrm{~cm}$, ou seja, $150 \mathrm{~mm}$. O número de folhas foi verificado contando-se as folhas sadias, caracterizadas como folhas sem manchas de doenças, inteiras e completamente desenvolvidas.

Os atributos de desenvolvimento e de produção foram avaliados no florescimento e na colheita das plantas de bananeiras da Thap Maeo e Prata-Anã. Os atributos avaliados para a avaliação do desenvol- vimento das plantas em relação à precocidade das cultivares foram: intervalo em dias entre o plantio e o florescimento - avaliado por meio de inspeções semanais no bananal para a determinação da data de florescimento de cada planta, para a posterior determinação da precocidade das cultivares; número de folhas - avaliado por meio da contagem de folhas vivas, por ocasião da floração e da colheita,

Os atributos avaliados na produção de cachos das bananeiras foram: número de pencas por cacho e frutos na $2^{\text {a }}$ penca - os cachos foram colhidos no estádio $3 / 4$ normal, com os frutos apresentando quinas, e os lados mais largos, iniciando a fase arredondada com cerca de 30 - 34 mm de diâmetro. Após a colheita, os cachos foram despencados, para a contagem do número de pencas e o número de frutos na $2^{\text {a }}$ penca; comprimento e diâmetro do engaço e dos frutos - após o despencamento foi determinado o tamanho do engaço, delimitando o seu tamanho a $15 \mathrm{~cm}$ abaixo da inserção da última penca, determinada quando do corte do coração, e a $15 \mathrm{~cm}$ acima da inserção da primeira penca. $\mathrm{O}$ tamanho dos frutos (diâmetro e comprimento) foi medido na $2^{\text {a }}$ penca; peso do engaço, do cacho e dos frutos - o cacho (penca + engaço) foi pesado e, depois do despencamento, o engaço foi pesado, delimitando o seu tamanho a $15 \mathrm{~cm}$ abaixo da inserção da última penca, determinada quando do corte do coração, e a $15 \mathrm{~cm}$ acima da inserção da primeira penca. O peso dos frutos foi determinado pesando-se os frutos da $2^{\mathrm{a}}$ penca.

Os resultados de número de folhas e diâmetro do pseudocaule das bananeiras foram utilizados para calcular o índice de durabilidade das folhas (equação 1) e a taxa de crescimento absoluto do comprimento do pseudocaule (equação 2), adptados de Teixeira et al. (2007), conforme descritos abaixo:

$$
\mathrm{IDF}=100 \times \frac{N F C}{N F E} \quad \text { equação 1 }
$$

Em que:

$I D F=$ índice de durabilidade foliar (\%);

$N F C=$ número de folhas ativas na época da colheita do cacho;

$N F E$ = número de folhas ativas na época da emissão da inflorescência.

$$
\text { TCA }=\frac{C 2-C 1}{T 2-T 1} \quad \text { equação } 2
$$

Em que:

$T C A=$ taxa de crescimento absoluto para o intervalo de tempo entre as medidas um e dois $(\mathrm{cm}$ mês $\left.{ }^{-1}\right) ; C 1=$ medida do comprimento do pseudocaule na época um, 150 dias após o plantio (T1, em meses); 
$C 2$ = medida do comprimento do pseudocaule na colheita do cacho (T2, em meses).

As amostras foliares foram realizadas em cada subparcela, conforme recomendado por Borges (2004). As folhas coletadas foram padronizadas com aparência sadia, livres de queimaduras de sol e danos por insetos. As amostras foram retiradas da terceira folha das plantas de bananeira da parcela útil, coletando-se $25 \mathrm{~cm}$ da parte interna mediana do limbo, eliminando-se a nervura central. Após a amostragem, os pedaços das folhas foram colocados em sacos de papel e enviados ao laboratório de solos e folha da COMIGO (Cooperativa Agroindustrial dos Produtores Rurais do Sudoeste Goiano). No laboratório, as amostras passaram por limpeza rápida com água destilada, secas em estufa a $60^{\circ} \mathrm{C}$ por $24 \mathrm{~h}$ e moídas para fazer as análises desejadas. Os teores de N, P, K, Ca, Mg, $\mathrm{S}, \mathrm{B}, \mathrm{Cu}, \mathrm{Fe}, \mathrm{Mn}$ e $\mathrm{Zn}$ nas amostras foliares das bananeiras foram analisados seguindo metodologia da Embrapa (2009).

Os dados obtidos foram submetidos às análises de variância. A significância dos coeficientes da ANOVA foram testados pelo teste $\mathrm{F}$, ao nível de 1 e $5 \%$ de probabilidade. As médias dos dados obtidos significativos pelo teste $\mathrm{F}$ foram comparadas entre si pelo teste de Tukey a 5\%. As análises de variância, do teste F e de Tukey foram feitas utilizando o software SAEG - Sistema para Análises Estatísticas, versão 9.1 (RIBEIRO_JÚNIOR, 2001). Foram ajustadas curvas de regressão, considerando os níveis de $\mathrm{N}$ e $\mathrm{K}$ como variáveis independentes, o desenvolvimento das bananeiras, a produção das bananeiras e os teores de macro e micronutrientes das folhas como variáveis dependentes.

\section{RESULTADOS E DISCUSSÃO}

A altura da planta na Thap Maeo e o número de folhas na Prata-Anã avaliados aos 150 DAT foram influenciados pelas doses combinadas de $\mathrm{N}$ e K. Entretanto, não mostraram diferença significativa entre as diferentes combinações utilizadas (Tabela 3). As adubações com $\mathrm{N}$ e K não favoreceram o desenvolvimento inicial das bananeiras Thap Maeo e Prata-Anã. Isso ocorreu devido ao solo apresentar altos teores de potássio na camada de 0-20 (Tabela 1).

Borges e Souza (2010) argumentam que, quando os níveis de $\mathrm{K}$ no solo estão entre $0,16 \mathrm{e}$ $0,30 \mathrm{cmol}_{\mathrm{c}} \mathrm{dm}^{-3}$, a adubação potássica deve ser iniciada a partir dos 30 dias após o transplantio, parcelando essa adubação em 4 meses para a formação do bananal. Nesse sentido, o solo da área de transplantio da Thap Maoe e Prata-Anã (Tabela 1) apresentou teor de $\mathrm{K}$ de $0,20 \mathrm{cmol}_{\mathrm{c}}$ $\mathrm{dm}^{-3}$, ou seja, $80 \mathrm{mg} \mathrm{dm}^{-3}$ na camada de $0-20 \mathrm{~cm}$ de profundidade. Assim, mesmo parcelando as adubações combinadas e potássicas, não houve efeito para o desenvolvimento inicial das bananeiras Thap Maeo e Prata-Anã. Portanto, esse solo supriu as necessidades de K da Thap Maeo e Prata-Anã pelo período de $150 \mathrm{DAT}$.

As diferentes doses combinadas de $\mathrm{N}$ e $\mathrm{K}$ proporcionaram regressões polinomiais significativas para diâmetro do pseudocaule e número de folhas na Thap Maeo e altura de plantas e diâmetro de pseudocaule na Prata-Anã, avaliados aos 150 DAT (Figura 1). Brasil et al. (2000), utilizando diferentes doses de $\mathrm{N}$ e $\mathrm{K}$ na cultivar Pioneira, descrevem que os tratamentos com doses de $\mathrm{N}$ e K não apresentaram efeito significativo em relação à altura de plantas, diâmetro do pseudocaule e número de folhas no início do desenvolvimento da cultura. $\mathrm{O} \mathrm{N}$ tem grande influência no crescimento inicial da bananeira, principalmente quando o meristema se encontra em fase de desenvolvimento. A bananeira, independentemente da cultivar, extrai maiores quantidades de $\mathrm{K}$ que de $\mathrm{N}$ durante o ciclo de formação das plantas. Neste trabalho, pôde-se observar que as doses combinadas de $\mathrm{N}$ e $\mathrm{K}$ favoreceram o desenvolvimento inicial das cultivares de bananeiras pelas regressões polinomiais significativas (Figura 1).

Espíndola et al.(2006), em um experimento, plantaram mudas de bananeiras consorciadas com leguminosas que fixam nitrogênio, comparando o desenvolvimento de bananeiras consorciadas com leguminosas com a área onde as bananeiras foram desenvolvendo-se com vegetação espontânea, verificaram que as bananeiras consorciadas tiveram maior desenvolvimento inicial no quarto mês após o plantio e nos demais meses até a produção, quando comparadas às bananeiras plantadas na área de vegetação espontânea. $\mathrm{O}$ fornecimento de $\mathrm{N}$ fixado pelas plantas leguminosas mostrou influenciar no desenvolvimento inicial das bananeiras. As cultivares deste trabalho também tiveram influência em seu desenvolvimento inicial pelo fornecimento de doses crescentes de N (Figura 1).

As doses crescentes e combinadas de $\mathrm{N}$ e $\mathrm{K}$ afetaram o intervalo de dias entre o florescimento e a colheita, dias entre o plantio e a colheita, e o comprimento do engaço na Thap Maeo (Tabela 4). A precocidade de emissão da inflorescência é um parâmetro da avaliação do potencial produtivo das bananeiras. Menor intervalo de tempo entre o plantio e o florescimento ou a colheita e novo 
florescimento é desejável em qualquer cultivar de bananeira. A dose de $300 \mathrm{~kg} \mathrm{ha}^{-1} \mathrm{ano}^{-1}$ de $\mathrm{N}$ e 450 $\mathrm{kg} \mathrm{ha}^{-1} \mathrm{ano}^{-1}$ de $\mathrm{K}$ reduziu o intervalo de dias entre florescimento e a colheita quando comparado com os demais tratamentos na Thap Maeo (Tabela 4). Corroborando este trabalho, Teixeira (2000), em um trabalho com doses crescentes de $\mathrm{N}$ e $\mathrm{K}$ em bananeira cultivar Nanicão, observou que doses crescentes de $\mathrm{N}$ anteciparam a emissão da inflorescência.

As diferentes combinações de dose de $\mathrm{N}$ e $\mathrm{K}$ proporcionaram regressões polinomiais significativas para os parâmentros de altura de plantas, diâmetro do pseudocaule, dias entre o plantio e a colheita, peso do cacho, número de pencas, peso do engaço, diâmetro do engaço e número de frutos na segunda penca, na Thap Maeo (Tabela 5 e Figura 2). A Thap Maeo apresentou altura de plantas de 2,56 m e 12,71 folhas no florescimento, no primeiro ciclo produtivo, em um experimento desenvolvido por Santos et al. (2006), o qual caracterizou cultivares de bananeiras resistentes a Sigatoka-Negra em Jataí-GO, em três ciclos produtivos com irrigação. $\mathrm{O}$ experimento desenvolvido em Rio Verde-GO foi em sequeiro e não teve irrigação suplementar; assim, as plantas de bananeira apresentaram menor porte quando comparadas ao trabalho de Santos et al. (2006).

A Prata-Anã foi influenciada pelas diferentes combinações de doses de $\mathrm{N}$ e K nos parâmetros diâmetro do pseudocaule, diâmetro do engaço, comprimento do fruto na segunda penca e peso do fruto na segunda penca. Entretanto, não mostrou diferença significativa entre as diferentes combinações utilizadas (Tabela 4).

As diferentes combinações de doses de $\mathrm{N}$ e $\mathrm{K}$ proporcionaram regressões polinomiais significativas para os parâmetros de diâmetro do pseudocaule, número de folhas, dias entre o plantio e o florescimento, dias entre o florescimento e a colheita, dias entre o plantio e a colheita, peso do cacho, número de pencas, número de frutos na segunda penca e taxa de crescimento absoluto na Prata-Anã (Tabela 6 e Figura 2). Corroborando essa pesquisa, Santos et al. (2009) verificaram que doses crescentes N e K aplicadas por fertirrigação em Latossolo VermelhoAmarelo aumentaram o número de frutos por penca e o número de pencas na produção de bananas da cultivar Prata-Anã, proporcionando regressão linear.

A TCA reflete o vigor da bananeira (TEIXEIRA et al., 2007). Dessa forma, a taxa de crescimento absoluto do pseudocaule (TCA) não se diferenciou estatisticamente entre o tratamento na Thap Maeo e na Prata-Anã, mas mostrou regressão polinomial significativa na Prata-Anã (Tabela 6 e
Figura 2).

As diferentes doses combinadas de $\mathrm{N}$ e $\mathrm{K}$ proporcionaram regressões polinominais significativas para os teores de $\mathrm{K}, \mathrm{Ca}, \mathrm{Mg}, \mathrm{S}, \mathrm{B}, \mathrm{Cu}$ e $\mathrm{Mn}$ na Thap Maeo. Os teores de K na folhas da Thap Maeo foram proporcionalmente maiores quando se aplicou a dose de $600 \mathrm{~kg} \mathrm{ha}^{-1} \mathrm{ano}^{-1}$ de $\mathrm{N}$ e $800 \mathrm{~kg}$ ha $^{-1}$ ano $^{-1}$ de K. Já os teores de $\mathrm{Ca}, \mathrm{Mg}, \mathrm{S}, \mathrm{B}$ e Cu nas folhas dessa cultivar foram menores à medida que se aumentavam as doses de N e K. Entretanto, os maiores teores foliares de Mn na Thap Maeo foram encontrados na dose de $300 \mathrm{~kg} \mathrm{ha}^{-1} \mathrm{ano}^{-1}$ de N e $450 \mathrm{~kg} \mathrm{ha}^{-1}$ ano $^{-1}$ de $\mathrm{K}$ (Figura 3).

Os teores de N, Ca, Mg, B, Cu e Fe nas folhas da Prata-Anã foram influenciados pelas combinações de doses de $\mathrm{N}$ e $\mathrm{K}$, resultando em regressões polinomiais significativas. Os teores foliares de N na Prata-Anã foram proporcionalmente maiores que doses combinadas de $\mathrm{N}$ e $\mathrm{K}$. Já os teores foliares de $\mathrm{Ca}, \mathrm{Mg}, \mathrm{B}, \mathrm{Cu}$ e $\mathrm{Fe}$ diminuíram com a aplicação de doses crescentes e combinadas de $\mathrm{N}$ e K (Figura 3).

As doses crescentes e combinadas de $\mathrm{N}$ e $\mathrm{K}$ favoreceram a atuação dos microrganismos na decomposição da matéria orgânica do solo, fornecendo maiores quantidades de micronutriente para as plantas de bananeira, no caso do Mn. Os micronutrientes nos solos, principalmente em Latossolos, estão relacionados à matéria orgânica. $\mathrm{O}$ nitrogênio é responsável por 5\% da matéria orgânica do solo. O processo de amonificação, nitrificação, mineralização, imobilização, desnitrificação e fixação de $\mathrm{N}_{2}$ ocorre com na presença de microrganismos presentes na matéria orgânica do solo. A disponibilidade de micronutrientes no solo está relacionada com a mineralização da matéria orgânica (MALAVOLTA, 2006).

Fontes et al. (2003) observaram, também, que há aumento nos teores foliares de Mn na planta de bananeira quando adubada com doses crescentes de N na cultivar Prata-Anã, na $1^{a}$ e $2^{a}$ gerações, justificando este aumento devido à maior solubilidade do $\mathrm{Mn}$ em função da possível redução do $\mathrm{pH}$ do solo, provocado pelo incremento das doses de $\mathrm{N}$. Estas duas explicações podem responder ao incremento do teor de Mn foliar na Prata-Anã, neste experimento, já que o solo do experimento tem níveis de matéria orgânica satisfatórios $\left(>30 \mathrm{~g} \mathrm{dm}^{-3}\right)$ para Latossolo, segundo Souza e Lobato (2004). Neste sentido, também pode ter ocorrido a redução do $\mathrm{pH}$ do solo com doses elevadas de $\mathrm{N}$ e $\mathrm{K}$, que acidificam o solo, solubilizando o Mn e prejudicando a absorção de B no caso da Thap Maeo.

As quantidades absorvidas de micronutrien- 
tes pelas bananeiras são relativamente altas e em maior proporção para $\mathrm{Mn}$ e Fe (AZEREDO et al., 1986). O Fe e o Mn foram os micronutrientes mais absorvidos nas folhas das cultivares de bananeira sob diferentes doses combinadas de $\mathrm{N}$ e $\mathrm{K}$.

Os teores foliares de $\mathrm{Mg}<1,5 \mathrm{~g} \mathrm{~kg}^{-1}$ foram verificados nas duas cultivares e nos tratamentos avaliados. A necessidade de $\mathrm{Mg}$ para um ótimo crescimento das plantas situa-se na faixa de 1,5 a $3,0 \mathrm{~g} \mathrm{~kg}^{-1}$ da matéria seca da parte vegetativa da planta. A deficiência de $\mathrm{Mg}$ ocorre com mais fre- quência em solos ácidos. Nos solos ácidos, o antagonismo por cátions em excesso $\left(\mathrm{H}^{+}, \mathrm{Al}^{3+}, \mathrm{Mn}^{2+}\right.$, $\mathrm{Fe}^{2+}$ ) pode causar a carência de $\mathrm{Mg}$. $\mathrm{O}$ excesso de $\mathrm{K}$ na adubação pode induzir a deficiência de $\mathrm{Mg}$, devido ao aumento da relação $\mathrm{K} / \mathrm{Mg}$, e doses muito elevadas de adubos potássicos podem provocar a lixiviação de $\mathrm{Mg}$ para camadas mais profundas do perfil (VITTI et al., 2006). Entretanto, este fato não ocorreu no presente estudo (Figura 3).

TABELA 1 - Resultados de pH, cálcio (Ca), magnésio $(\mathrm{Mg})$, alumínio ( $\mathrm{Al})$, hidrogênio + alumínio ( $\mathrm{H}+\mathrm{Al})$, capacidade de troca catiônica (CTC), potássio (K), fósforo (P), matéria orgânica (M.O.), areia, silte, argila e saturação por bases (V) do Latossolo Vermelho distrófico da área de plantio das bananeiras.

\begin{tabular}{|c|c|c|c|c|c|c|c|c|c|c|c|c|}
\hline rofundidade & pH & Ca & Mg & Al & $\mathbf{H}+\mathbf{A l}$ & CTC & $\mathbf{K}$ & $\mathbf{P}$ & M.O. & Areia Silte & Argila & V \\
\hline (cm) & $\left(\mathrm{CaCl}_{2}\right.$ & ) - & . & . & $\mathrm{dm}^{-3}$ & 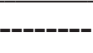 & $--m g d$ & $\mathrm{dm}^{-3}--$ & ---- & 0 & 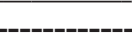 & 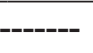 \\
\hline $0-10$ & 4,8 & 1,66 & 0,54 & 0,15 & 4,00 & 6,46 & 101,70 & 8,72 & 3,14 & 61,04 & 32,38 & 38,08 \\
\hline $10-20$ & 4,6 & 1,13 & 0,35 & 0,26 & 4,60 & 6,23 & 58,70 & 16,63 & 3,01 & 54,36 & 38,96 & 26,16 \\
\hline $20-40$ & 4,4 & 0,74 & 0,25 & 0,36 & 4,30 & 5,37 & 31,30 & 4,11 & 2,11 & 61,04 & 32,28 & 19,93 \\
\hline $40-60$ & 4,6 & 0,52 & 0,11 & 0,14 & 3,40 & 4,09 & 23,50 & 1,89 & 1,64 & 54,36 & 38,96 & 16,87 \\
\hline
\end{tabular}

TABELA 2 - Quantidade de nitrogênio $(\mathrm{N})$ e de potássio $\left(\mathrm{K}_{2} \mathrm{O}\right)$ aplicadas em cada tratamento nas bananeiras Thap Maeo e Prata-Anã.

\begin{tabular}{ccc}
\hline Tratamentos & Quantidade de N & Quantidade de $\mathbf{K}_{2} \mathbf{O}$ \\
\hline & $------\mathbf{k g ~ h a}^{-1} \mathbf{a n o}^{-1}--$ & 0 \\
N0/K0 & 0 & 300 \\
N1/K1 & 150 & 450 \\
N2/K2 & 300 & 600 \\
N3/K3 & 450 & 800 \\
N4/K4 & 600 & \\
\hline
\end{tabular}

TABELA 3 - Altura de plantas e número de folhas das cultivares de banana aos 150 D.A.P.

\begin{tabular}{|c|c|c|c|c|c|c|c|c|}
\hline \multirow{2}{*}{$\begin{array}{l}\text { Atributos da } \\
\text { bananeira }\end{array}$} & \multicolumn{5}{|c|}{ Tratamentos } & \multirow[b]{2}{*}{ Média } & \multirow[b]{2}{*}{ Valor de $\mathrm{F}^{1}$} & \multirow[b]{2}{*}{$\mathrm{CV} \%$} \\
\hline & $\mathrm{N} 0 / \mathrm{K} 0$ & $\mathrm{~N} 1 / \mathrm{K} 1$ & $\mathrm{~N} 2 / \mathrm{K} 2$ & N3/K3 & $\mathrm{N} 4 / \mathrm{K} 4$ & & & \\
\hline & & & ----Thap & Maeo---- & & & & 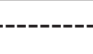 \\
\hline Altura $(\mathrm{cm})$ & $89,67 a^{2}$ & $126,33 \mathrm{a}$ & $125,67 \mathrm{a}$ & $129,72 \mathrm{a}$ & $118,42 \mathrm{a}$ & 117,96 & $4,44 * *$ & 12,39 \\
\hline Número de folhas & $12,22 \mathrm{a}$ & $12,94 \mathrm{a}$ & $13,56 \mathrm{a}$ & $12,33 \mathrm{a}$ & $11,00 \mathrm{a}$ & 12,41 & $5,42 *$ & 6,86 \\
\hline
\end{tabular}

${ }^{1}$ Valor de F; *Significativo a $5 \%$; **Significativo a $1 \%$;

${ }^{2}$ Valores seguidos por letras iguais na linha não diferem entre si, pelo teste de Tukey a $5 \%$. 
TABELA 4 - Atributos de desenvolvimento e produção da Thap Maeo e Prata-Anã com diferentes níveis de adubação nitrogenada e potássica no primeiro ciclo produtivo.

\begin{tabular}{|c|c|c|c|c|c|c|c|c|}
\hline \multirow{2}{*}{$\begin{array}{c}\text { Atributos avaliados nas } \\
\text { bananeiras }\end{array}$} & \multicolumn{5}{|c|}{ Tratamentos } & \multirow{2}{*}{$\begin{array}{l}\text { Mé- } \\
\text { dias }\end{array}$} & \multirow{2}{*}{$\begin{array}{l}\text { Valor } \\
\text { de F } F^{1} \\
\end{array}$} & \multirow[b]{2}{*}{$\mathrm{CV} \%$} \\
\hline & $\mathrm{N} 0 / \mathrm{K} 0$ & $\mathrm{~N} 1 / \mathrm{K} 1$ & $\mathrm{~N} 2 / \mathrm{K} 2$ & $\mathrm{~N} 3 / \mathrm{K} 3$ & $\mathrm{~N} 4 / \mathrm{K} 4$ & & & \\
\hline \multicolumn{9}{|c|}{ 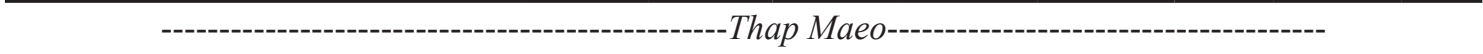 } \\
\hline dias entre o florescimento à colheita & $133,67 \mathrm{a}^{2}$ & $127,50 \mathrm{a}$ & $102,00 \mathrm{~b}$ & $122,50 \mathrm{ab}$ & $123,33 \mathrm{ab}$ & 121,8 & $3,89 * *$ & 8,75 \\
\hline dias entre o plantio à colheita ${ }^{4}$ & $501,67 \mathrm{a}$ & $465,00 \mathrm{a}$ & $461,00 \mathrm{a}$ & $476,00 \mathrm{a}$ & 471,67 a & 475,07 & $3,53 * *$ & 3,01 \\
\hline comprimento do engaço $(\mathrm{cm})$ & $66,00 \mathrm{a}$ & $67,00 \mathrm{a}$ & $57,00 \mathrm{a}$ & $58,83 \mathrm{a}$ & $63,00 \mathrm{a}$ & 62,37 & $5,91 *$ & 6,27 \\
\hline & & 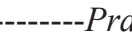 & ala- & & & & ---- & \\
\hline diâmetro do pseudocaule (cm) & $11,77 \mathrm{a}$ & $12,34 \mathrm{a}$ & $13,94 \mathrm{a}$ & $14,40 \mathrm{a}$ & 13,86 a & 13,26 & $4,52 * *$ & 7,68 \\
\hline diâmetro do engaço $(\mathrm{cm})$ & $4,63 \mathrm{a}$ & $4,90 \mathrm{a}$ & $4,12 \mathrm{a}$ & $4,35 \mathrm{a}$ & $4,49 \mathrm{a}$ & 4,5 & $6,12 *$ & 5,86 \\
\hline comp. do fruto na $2^{a}$ penca $(\mathrm{cm})^{5}$ & $8,33 \mathrm{a}$ & $7,47 \mathrm{a}$ & $8,17 \mathrm{a}$ & $8,67 \mathrm{a}$ & $5,42 \mathrm{a}$ & 7,61 & $9,36^{*}$ & 15,3 \\
\hline peso de frutos na $2^{\mathrm{a}}$ penca $(\mathrm{g})$ & $56,67 \mathrm{a}$ & $50,00 \mathrm{a}$ & $70,00 \mathrm{a}$ & $66,67 \mathrm{a}$ & $46,67 \mathrm{a}$ & 58,89 & $4,06^{* *}$ & 15,68 \\
\hline
\end{tabular}

${ }^{1}$ Valor de F; *Significativo a 5\%; **Significativo a $1 \%$;

${ }^{2}$ Valores seguidos por letras iguais na linha não diferem entre si, pelo teste de Tukey a 5\%;

${ }^{3}$ Duração de dias entre o florescimento e a colheita das bananeiras;

${ }^{4}$ Duração de dias entre o plantio e a colheita das bananeiras;

${ }^{5}$ Comprimento de frutos na $2^{\mathrm{a}}$ penca do cacho de banana colhido.

TABELA 5 - Equações de regressão (y) e coeficientes de determinação $\left(\mathrm{R}^{2}\right)$ dos atributos de desenvolvimento e produção da Thap Maeo com doses crescentes e combinadas de $\mathrm{N}$ e K.

\begin{tabular}{llc}
\hline \multicolumn{1}{c}{ Atributos avaliados nas bananeiras } & \multicolumn{1}{c}{ Equação polinomial } & $\mathbf{R}^{2}$ \\
\hline altura de plantas $(\mathrm{cm})^{1}$ & $\mathrm{y}=2,02+0,038 \mathrm{x}+0,0084 \mathrm{x}^{2}$ & $0,96^{*}$ \\
diâmetro do pseudocaule $(\mathrm{cm})^{2}$ & $\mathrm{y}=12,95+0,181 \mathrm{x}-0,0157 \mathrm{x}^{2}$ & $0,75^{* *}$ \\
dias entre o plantio e a colheita & $\mathrm{y}=496,82-28,805 \mathrm{x}+5,9762 \mathrm{x}^{2}$ & $0,72^{* *}$ \\
peso do cacho $(\mathrm{kg})$ & $\mathrm{y}=4,76+1,895 \mathrm{x}-0,4976 \mathrm{x}^{2}$ & $0,78^{* *}$ \\
número de pencas & $\mathrm{y}=6,17+1,790 \mathrm{x}-0,381 \mathrm{x}^{2}$ & $0,91 *$ \\
peso do engaço $(\mathrm{kg})$ & $\mathrm{y}=0,846-0,263 \mathrm{x}+0,0546 \mathrm{x}^{2}$ & $0,99 *$ \\
diâmetro do engaço $(\mathrm{cm})$ & $\mathrm{y}=4,05-0,419 \mathrm{x}+0,1048 \mathrm{x}^{2}$ & $0,81 * *$ \\
número de frutos na 2 ${ }^{\mathrm{a}}$ penca & $\mathrm{y}=7,68+4,529 \mathrm{x}-0,857 \mathrm{x}^{2}$ & $0,80^{* *}$ \\
\hline
\end{tabular}

${ }^{1}$ Altura de plantas no florescimento;

${ }^{2}$ Diâmetro de plantas no florescimento;

*Significativo a 5\%; **Significativo a $1 \%$, pelo teste $\mathrm{F}$.

TABELA 6 - Equações de regressão (y) e coeficientes de determinação $\left(\mathrm{R}^{2}\right)$ dos atributos de desenvolvimento e produção da Prata-Anã com doses crescentes e combinadas de N e K.

\begin{tabular}{llc}
\hline \multicolumn{1}{c}{ Atributos avaliados nas bananeiras } & \multicolumn{1}{c}{ Equação polinomial } & $\mathbf{R}^{2}$ \\
\hline diâmetro do pseudocaule $(\mathrm{cm})^{1}$ & $\mathrm{y}=11,53+1,586 \mathrm{x}-0,2407 \mathrm{x}^{2}$ & $0,91^{* *}$ \\
número de folhas no florescimento & $\mathrm{y}=9,37+0,698 \mathrm{x}-0,11786 \mathrm{x}^{2}$ & $0,96^{*}$ \\
dias entre plantio e florescimento & $\mathrm{y}=334,51-8,303 \mathrm{x}-0,5437 \mathrm{x}^{2}$ & $0,83^{* *}$ \\
dias entre o florescimento e a colheita & $\mathrm{y}=132,28-44,852 \mathrm{x}+10,738 \mathrm{x}^{2}$ & $0,99^{*}$ \\
dias entre o plantio e a colheita & $\mathrm{y}=466,78-53,156 \mathrm{x}+10,194 \mathrm{x}^{2}$ & $0,91^{* *}$ \\
peso do cacho (kg) & $\mathrm{y}=4,87-0,341 \mathrm{x}+0,0229 \mathrm{x}^{2}$ & $0,94^{*}$ \\
número de pencas & $\mathrm{y}=4,87-0,341 \mathrm{x}+0,0229 \mathrm{x}^{2}$ & $0,94^{*}$ \\
número de frutos na $2^{\mathrm{a}}$ penca & $\mathrm{y}=6,51+3,27 \mathrm{x}-0,6448 \mathrm{x}^{2}$ & $0,82^{* *}$ \\
taxa de crescimento $\left(\mathrm{cm} \mathrm{mês}{ }^{-1}\right)$ & $\mathrm{y}=16,28+2,398 \mathrm{x}-0,6923 \mathrm{x}^{2}$ & $0,97^{*}$ \\
\hline
\end{tabular}

${ }^{1}$ Diâmetro de plantas no florescimento;

*Significativo a $5 \%$; **Significativo a $1 \%$, pelo teste $\mathrm{F}$. 


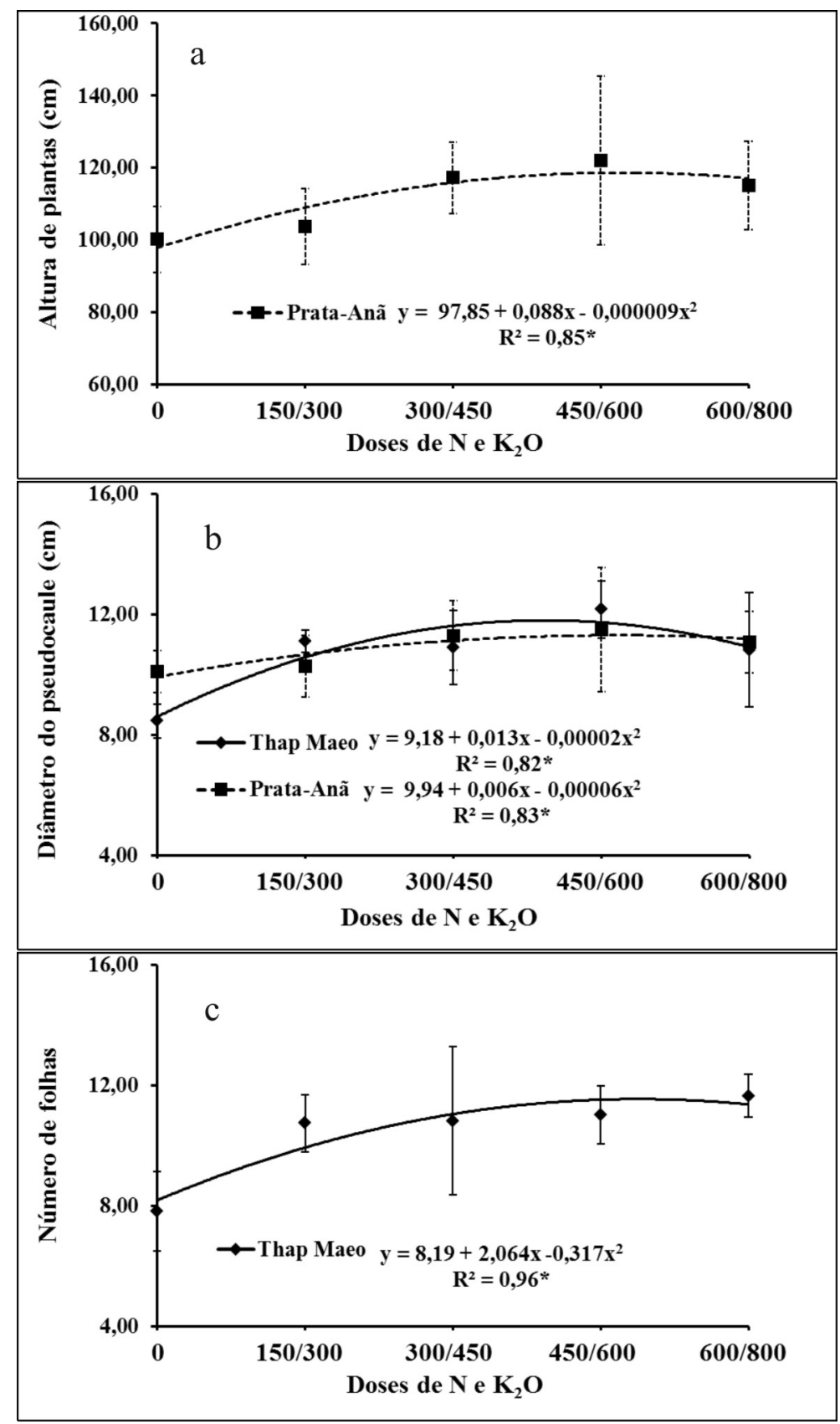

FIGURA 1 - Regressões polinomiais de altura de plantas (a), diâmetro do pseudocaule (b) e número de folhas aos 150 D.A.P. das bananeiras Thap Maeo e Prata-Anã adubadas com doses crescentes e combinadas de $\mathrm{N}$ e $\mathrm{K}$; *significativo $5 \%$; ** significativo $1 \%$, pelo teste $\mathrm{F}$. Barras sobre os pontos representam o erro-padrão da média. 
Thap Maeo

Prata-Anã

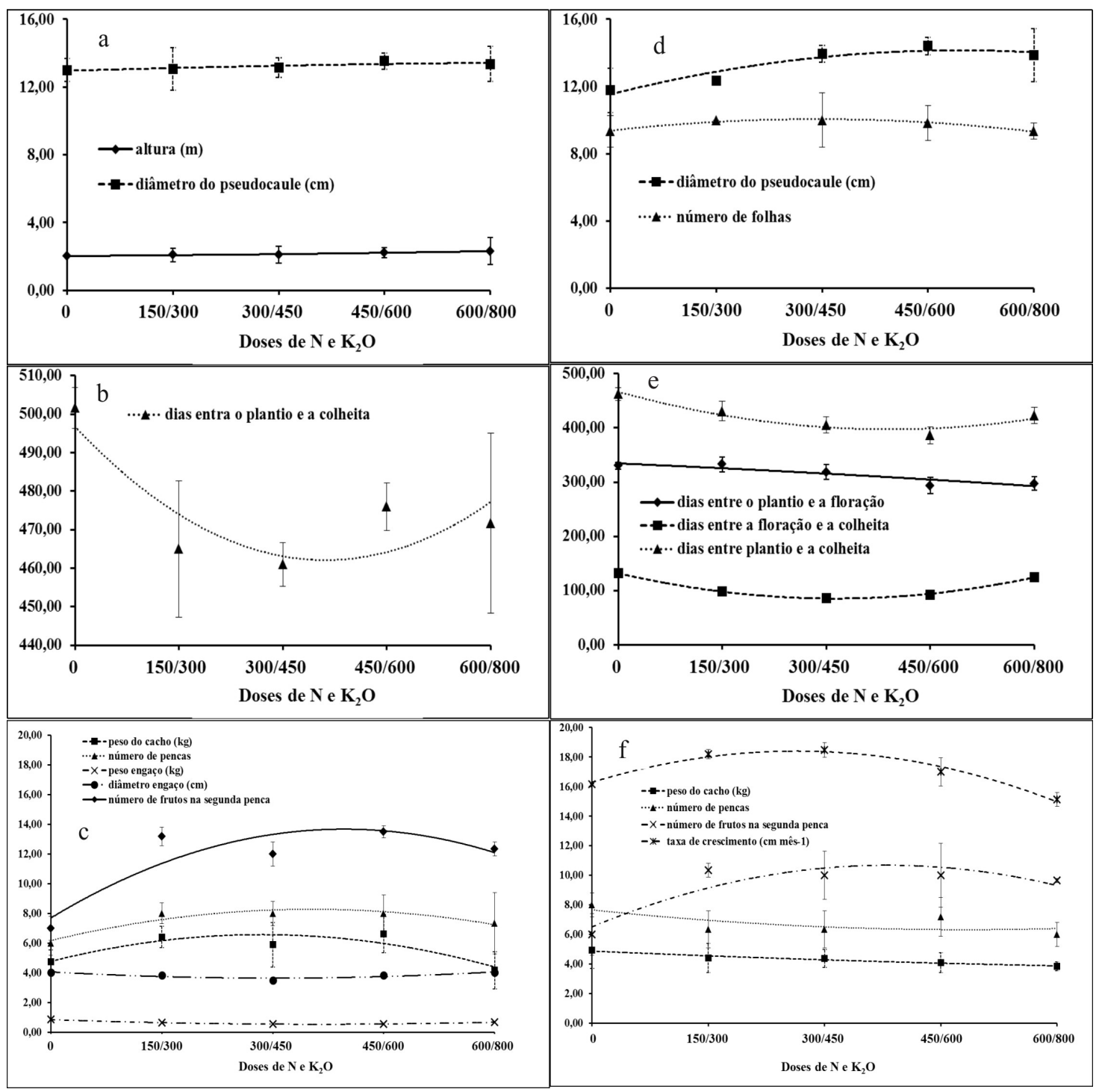

FIGURA 2 - Regressões polinomiais significativas dos atributos de desenvolvimento e produção da Thap Maeo e Prata-Anã; Thap Maeo: a) altura (cm), diâmetro do pseudocaule (cm); b) dias entre o plantio e a colheita; c) peso do cacho $(\mathrm{kg})$, número de pencas, peso engaço $(\mathrm{kg})$, diâmetro do engaço $(\mathrm{cm})$, número de frutos na segunda penca. Prata-Anã: d) diâmetro do pseudocaule $(\mathrm{cm})$ e número de folhas; e) dias entre o plantio e a floração, dias entre a floração e a colheita, e dias entre o plantio e a colheita; f) peso do cacho $(\mathrm{kg})$, número de pencas, número de frutos na segunda penca e taxa de crescimento $\left(\mathrm{cm} \mathrm{mês}^{-1}\right)$. Barras sobre os pontos representam o erro-padrão da média. 


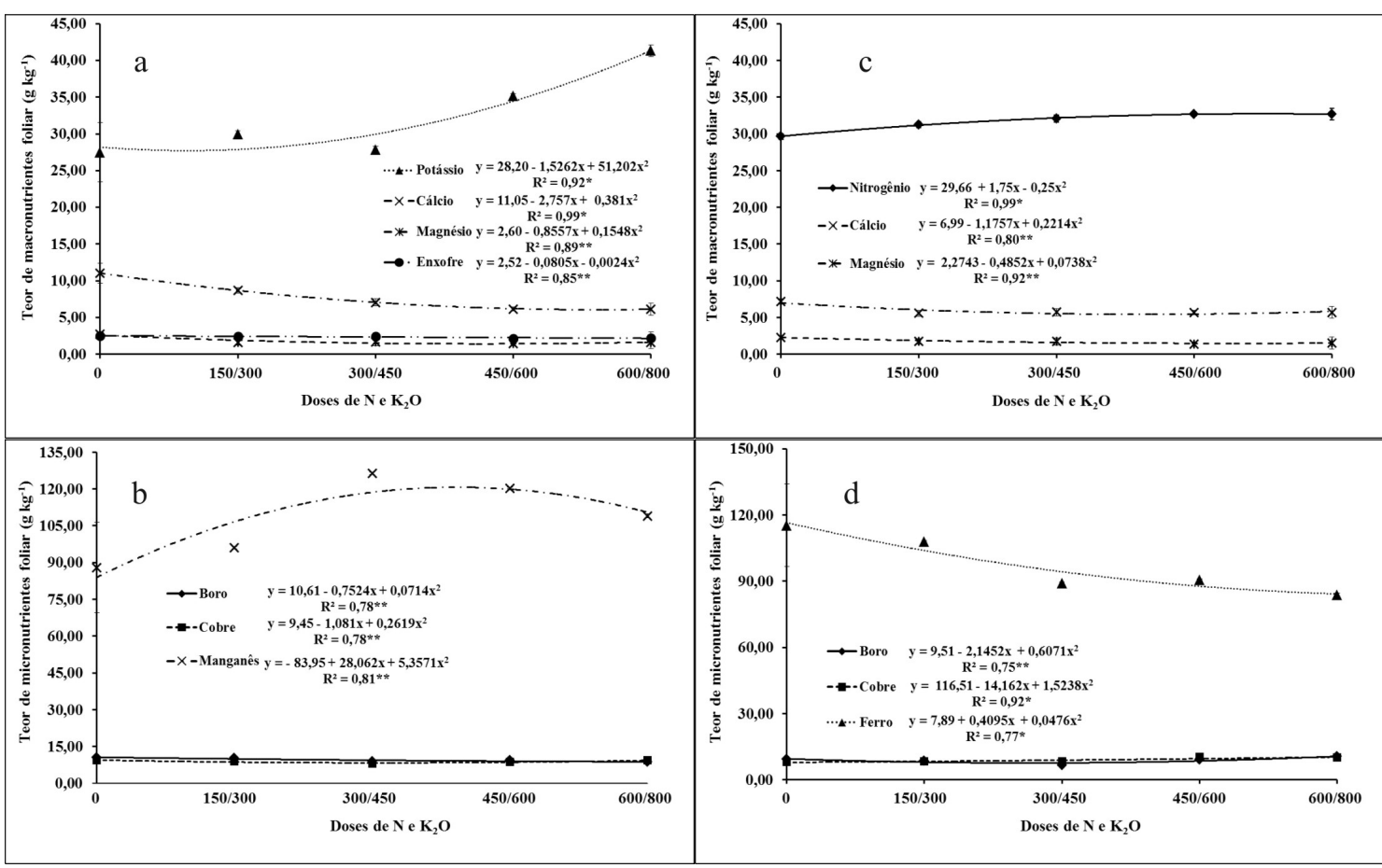

FIGURA 3 - Regressões polinomiais para os teores de macronutrientes $(\mathrm{a} ; \mathrm{c})$ e micronutrientes $(\mathrm{b} ; \mathrm{d})$ nas folhas de bananeira Thap Maeo e Prata-Anã adubadas com doses crescentes e combinadas de $\mathrm{Ne} \mathrm{K}$; *significativo 5\%; **significativo 1\%, pelo teste $\mathrm{F}$. Barras sobre os pontos representam o erro-padrão da média.

\section{CONCLUSÃO}

A aplicação de $300 \mathrm{~kg} \mathrm{ha}^{-1}$ ano $^{-1}$ de $\mathrm{N}$ e 450 $\mathrm{kg} \mathrm{ha}^{-1} \mathrm{ano}^{-1}$ de K parcelada em 4 vezes promoveu a precocidade entre o florescimento e a colheita para a cultivar Thap Maeo. As diferentes combinações de doses de $\mathrm{N}$ e $\mathrm{K}$ promovem o desenvolvimento e a produção da Prata-Anã, sendo que não se identificou um melhor tratamento para recomendar a adubação com $\mathrm{N}$ e $\mathrm{K}$ nessa cultivar. As diferentes doses combinadas de $\mathrm{N}$ e $\mathrm{K}$ influenciam nos teores foliares de K, Ca, Mg, S, B, Cu e Mn na Thap Maeo e de N, Ca, Mg, B, Cu e Fe na Prata-Anã.

\section{AGRADECIMENTOS}

À Cooperativa Agroindustrial dos Produtores Rurais do Sudoeste Goiano - COMIGO, pelo financiamento e pela concessão da área para realização deste trabalho de pesquisa.

\section{REFERÊNCIAS}

ALVAREZ, C. E.; ORTEGA, A.; FERNÁNDEZ, M.; BORGES, A. A. Growth, yield and leaf nutrient content of organically grown banana plants in the Canary islands. Fruits, Valencia, v. 56, p. 17-26, 2001.

AZEREDO, J. A. D.; GENÜ, P. J. D. C.; AQUINO, A. R. L. D.; CAMPELO JÚNIOR, J. H.; RODRIGUEZ, A. P. M. Nutrição mineral e adubação da bananeira. In: HAAG, P. H. (Ed.). Nutrição mineral e adubação de frutíferas tropical no Brasil. Campinas: Fundação Cargill, 1986, p. 58-102.

BORGES, A. L. Banana em foco-diagnose química foliar em bananeira. Cruz das Almas: Embrapa Mandioca e Fruticultura, 2004, 2 p. 
BORGES, A. L.; SILVA, J. T. A.; OLIVEIRA, S. L. Adubação nitrogenada e potássica para bananeira cv. Prata-Anã irrigada: produção e qualidade dos frutos no primeiro ciclo. Revista Brasileira de Fruticultura, Jaboticabal, 19, n. 2, p. 179-184, 1997.

BORGES, A. L.; SOUZA, L. S. Recomendações para calagem e adubação da bananeira. Cruz das Almas: Embrapa Mandioca e Fruticultura, 2010. 5p. (Comunicado Técnico 137).

BRASIL, E. C.; OEIRAS, A. H. L.; MENEZES, A.; VELOSO, C. A. C. Desenvolvimento e produção de frutos de bananeira em resposta à adubação nitrogenada e potássica. Pesquisa Agropecuária Brasileira, Brasília, v. 35, n. 12, p. 2407-2414, 2000.

CANTARUTTI, R. B.; MAIA, V. M.; SALOMÃO, L. C. C.; VENEGAS, V. H. A.; LIMA, S. Efeitos das doses de nitrogênio, fósforo e potássio sobre os componentes da produção e a qualidade de bananas Prata-Anã. In: CONGRESSO BRASILEIRO DE FRUTICULTURA., 16. 2000, Fortaleza. Anais...

CORDEIRO, Z. J. Banana. Produção: aspectos técnicos. Brasilia: Embrapa, 2000. 143 p.

DONATO, S. L. R.; SILVA, S.; LUCCA FILHO, O. A.; LIMA, M. B.; DOMINGUES, H.; ALVES, J. Comportamento de variedades e híbridos de bananeira (Musa spp.), em dois ciclos de produção no sudoeste da Bahia. Revista Brasileira de Fruticultura, Jaboticabal, v. 28, n. 1, p. 139-144, 2006.

EMBRAPA. Manual de análises químicas de solos, plantas e fertilizantes. 2. ed. Brasília: Embrapa Informação Tecnológica, 2009. 627 p.

EPAGRI - Centro de Socioeconomia e Planejamento agrícola. Banana: panorama mundial, nacional e estadual das ultimas safras. Disponível em: $<\mathrm{http} / /$ cepa.epagri.sc.gov.br/>. Acesso em: 14 ago. 2009.

ESPINDOLA, J. A. A.; GUERRA, J. G. M.; PERIN, A.; TEIXEIRA, M. G.; DE ALMEIDA, D. L.; URQUIAGA, S.; BUSQUET, R. N. B. Bananeiras consorciadas com leguminosas herbáceas perenes utilizadas como coberturas vivas. Pesquisa Agro- pecuária Brasileira, Brasília, v. 41, n. 3, p. 415420, 2006.

FONTES, P. S. F.; CARVALHO, A. J. C.; CEREJA, B. S. Avaliação do estado nutricional e do desenvolvimento da bananeira-prata-anã (Musa spp.) em função da adubação nitrogenada. Revista Brasileira de Fruticultura, Jaboticabal, v. 25, n. 1, p. 156159, 2003.

GUERRA, A. G.; ZANINI, J. R.; NATALE, W.; PAVANI, L. C. Frequência da fertirrigação da bananeira Prata-Anã com nitrogênio e potássio aplicados por microaspersão. Engenharia Agrícola, Jaboticabal, v. 24, n. 1, p. 80-88, 2004.

GUERRERO, R. R.; GAGBAN, R. J. Eficacia de diferentes fertilizantes nitrogenados en el cultivo del banano (Musa AAA, Clon Valery), en la zona de Riofrío, Magdalena, Colombia. In. ENCUENTRO DE ACORBAT, 15., 2002. Cartagena del India, 2002.

IBGE. Levantamento sistemático da produção agrícola. 2010. Disponível em: $\leq$ http://www.sidra.ibge. gov.br/bda/prevsaf $/$ default.asp? $\mathrm{z}=\mathrm{t} \& \mathrm{o}=10 \& \mathrm{i}=\mathrm{P}>$. Acesso em: 30 mar. 2011

LOPES, A. S. Acidez do solo e calagem. 3. ed. São Paulo: ANDA, 1990. 22 p.

MALAVOLTA, E. Manual de nutrição mineral de plantas. São Paulo: Agronômica Ceres, 2006. $638 \mathrm{p}$

RIBEIRO_JÚNIOR, J. I. Análises estatísticas no SAEG. Viçosa: UFV, 2001. 301 p.

SANTOS, S. C.; CARNEIRO, L. C.; DA SILVEIRA NETO, A. N.; JÚNIOR, E. P.; DE FREITAS, H. G.; PEIXOTO, C. N. Caracterização morfológica e avaliação de cultivares de bananeira resistentes a Sigatoka-Negra (Mycosphaerella fijiensis Morelet) no sudoeste Goiano. Revista Brasileira de Fruticultura, Jaboticabal, v. 28, n. 3, p. 449-453, 2006

SANTOS, V. P. D.; FERNANDES, P. D.; MELO, A. S. D.; SOBRAL, L. F.; BRITO, M. E. B.; DANTAS, J. D. D. M.; BONFIM, L. V. Fertirrigação da bananeira cv. Prata-Anã com N e K em um Argisso- 
lo Vermelho-Amarelo. Revista Brasileira de Fruticultura, Jaboticabal, v. 31, p. 567-573, 2009.

SILVA, J. T. A.; BORGES, A. L.; CARVALHO, J. G. Adubação com potássio e nitrogênio em três cíclos de produção da bananeira cv. prata-anã. Revista Brasileira de Fruticultura, Jaboticabal, v. 25, n. 1, p. 152-155, 2003.

SOUSA, D. M. G.; LOBATO, E. Cerrado: correção do solo e adubação. 2.ed. Brasília: Embrapa Informação Tecnológica, 2004. 416p.

SOUSA, V. F. D.; COSTA VELOSO, M. E. D.; VASCONCELOS, L. F. L.; RIBEIRO, V. Q.; SOUZA, V. A. B. D.; JUNIOR, B. S. A. Nitrogênio e potássio via água de irrigação nas características de produção da bananeira'Grand Naine'. Pesquisa Agropecuária Brasileira, Brasília, v. 39, n. 9, p. 865-869, 2004.

TEIXEIRA, L. A. J. Adubação nitrogenada e potássica em bananeira Nanicão (Musa AAA subgrupo Cavendish) sob duas condições de irrigação. 2000. 145 f. (Doutorado em Agronomia,
Produção Vegetal) - Faculdade de Ciências Agrárias e Veterinárias, Universidade Estadual Paulista, Jaboticabal, 2000.

TEIXEIRA, L. A. J.; NATALE, W.; MARTINS, A. L. M. Nitrogênio e potássio via fertirrigação e adubação convencional-estado nutricional das bananeiras e produção de frutos. Revista Brasileira de Fruticultura, Jaboticabal, v. 29, n. 1, p. 153160, 2007.

VITTI, G. C.; LIMA, E.; CICARONE, F. Cálcio, magnésio e enxofre. In: FERNANDES, M. S. (Ed.). Nutrição mineral de plantas. Viçosa, MG: SBCS, 2006. p. 299-396.

WEBER, O. B.; MONTENEGRO, A. A. T.; SILVA, Í.; SOARES, I.; CRISÓSTOMO, L. A. Adubação nitrogenada e potássica em bananeira Pacovan (Musa AAB, subgrupo Prata) na chapada do Apodi, Estado do Ceará. Revista Brasileira de Fruticultura, Jaboticabal, v. 28, n. 1, p. 154-157, 2006. 